\title{
Analyst Downgrades, Short Sale Constraints, And Intra-Day Stock Price Efficiency
}

\author{
Kevin Zhao, Middle Tennessee State University, USA
}

\begin{abstract}
This paper studies the impact of short sale constraints on stock price efficiency upon arrival of analyst downgrades. Examining the speed of which stock price response to analyst downgrades for pilot (short sale non-constrained) stocks and control (short sale constrained) stocks in an intra-day setting, I find evidence supporting the hypothesis that short sale constrains hamper intra-day stock price efficiency. For after-hours downgrades, pilot stocks respond quickly, with virtually all of the price response incorporated by the following open, while control stocks take an extra five minutes after opening to fully reflect the new information. For during-hour downgrades, the negative information is partially incorporated into pilot stock prices up to two hours before the recommendation is released, while control stocks take up to an hour and a half after the release to impound the information into stock price, confirming that short sale constraints lower stock price efficiency.
\end{abstract}

Keywords: Analyst Downgrades; Short Sale Constraints; Uptick Rule; Stock Price Efficiency

\section{INTRODUCTION}

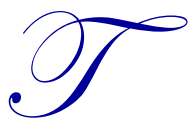

he existing literature shows that financial analysts' recommendations are informative and have incremental investment value (Womack, 1996; Kim et al., 1997; Barber et al., 2001; Brav and Lehavy, 2003; and Green, 2006). Yet the stock price reactions to analysts' upgrades and downgrades are asymmetric. Womack (1996) shows that bad news be incorporated into stock price much more slowly than good news. It has been hypothesized that short sale constraints prevent negative information from being registered into the stock price by restricting pessimistic investors from short selling while imposing no such restriction for optimistic investors (Miller, 1977; Diamond and Verrecchia, 1987). Recent empirical studies offer evidence that stock prices are less efficient when short sale constraints are in place (Bris et al., 2007; Saffi and Sigurdson, 2010; and Boehmer and $\mathrm{Wu}, 2007)$. However, these studies cannot directly reveal how actual short selling activity affects the informational efficiency of stock prices in an intra-day fashion due to data limitation. To fill this gap, this paper explores directly the mechanism in which short sale constraints hampers stock price efficiency by using high frequency data of short selling activity and stock prices. The unique study design in this paper is characterized by choosing analyst recommendations as information events, using the speed of price response to recommendation changes as the direct measures of stock price efficiency, and adopting the uptick rule exempt status as the proxy for short sale constraints. The uptick rule is a short sale constraint in which a short sale is only allowed at a price that is greater than or equal to the previous trading prices, known as the SEC 10a-1 Rule. Using the tick-by-tick Regulation SHO data from 2005 I examine the market response to the release of analyst downgrades for stocks that are exempt from uptick rule restrictions (pilot stocks) and stocks that are subject to such restrictions (control stocks).

For after-hour financial analyst downgrades, pilot stocks respond quickly, with virtually all of the price response incorporated by the following open, while control stocks take an extra five minutes after opening to fully reflect the new information. For downgrades that occur during normal trading hours, the information is partially incorporated into pilot stock prices up to two hours before the recommendation is released, while control stocks take up to an hour and a half to impound the information into stock price. Both results suggest that short sale constraint 
reduce the speed with which negative information is incorporated into stock prices. Given lower levels of nonexempt shorting in pilot stocks, rapid price response occurs, confirming the hypothesis that short sale constraints hamper the stock price efficiency.

This paper contributes to the literature in the following ways. First, the intra-day evidence of improved price efficiency due to the suspension of uptick rules extends recent studies on shorting-efficiency relationship. Due to the low frequency of the data, previous studies used cannot directly reveal how short sale constraints affect informational efficiency on an intra-day basis (Bris et al., 2007, Boehmer and $\mathrm{Wu}, 2013$, and Saffi and Sigurdsson, 2010). In this paper, high frequency data allows us to adopt the speed of price response to analyst downgrades as an intra-day direct measure of price efficiency.

Second, this paper adds to the literature that uses the Regulation SHO data to examine the impact of the pilot program on market quality (Diether et al., 2009a; Alexander and Peterson, 2008). While these studies examine general market quality measures such as bid-ask spread, bid and ask depth, liquidity, and volatility, this paper focuses on one key dimension of market quality, informational stock price efficiency. This study provides direct intra-day evidence on how short sale constraints affects stock price efficiency.

Third, this paper is related to the literature on the investment value of financial analyst recommendations. Green (2006) shows that early access to stock recommendations provides investors with $1.5 \%$ two day returns from shorting stocks with downgrade recommendation, and that the profit opportunities persist for only two hours following the pre-market release of analyst recommendation changes. This result highlights the speed at which private information is incorporated into stock prices and motivates us to use high frequency short selling data. This paper complements the literature by conducting an intra-day analysis of stock price response to analyst recommendations that are released during both after-hour and normal trading hour periods.

Nevertheless, this study has a number of limitations. First, I only use data on NYSE and this restricts our ability to generalize the conclusions to stocks listed on NASDAQ. Second, I only examine the impact of short selling on a specific information event-analyst downgrades. There may be other events for which the different information driven short selling patterns associated with the suspension of the uptick rule can be discovered. Third, due to limitations in data, I could not test whether after hour shorting and shorting at the market opening auction are important forces that contribute to the improved stock price efficiency. Such analyses would be an interesting and promising extension for future research.

The remainder of this paper proceeds as follows. Section 2 reviews the literature. Section 3 describes data and constructs samples. Section 4 conducts empirical tests. Section 5 concludes.

\section{LITERATURE REVIEW}

In this section, I review literature in three different areas: (1) Investment value of analyst recommendations; (2) Informativeness of short selling; and (3) Short sale constraints and stock price efficiency.

\subsection{Investment Value of Analyst Recommendations}

Existing literature suggests that sell-side analysts' recommendations have incremental investment value. For example, Womack (1996) examine the price and volume reactions to analyst's recommendation changes and provides evidence that brokerage firm analysts appear to have market timing and stock-picking ability. He documents a size-adjusted return of $-4.7 \%$ in the three-day event period window and a $-9.1 \%$ post-recommendation drift over a six-month post event period for sell recommendations in contrast to a $3 \%$ event window return and $2.4 \%$ short-lived post-event drift for buy recommendations. Consistent with Womack (1996)'s results, Barber et al. (2001) use a different method from a more investor-oriented calendar time perspective and find that a portfolio comprised of the most (or least) highly recommended stocks provides an average annual abnormal return of 4.13 (4.91)\%. In addition, Brav and Lehavy (2003) examine market reaction to analysts' target price announcement and find that target prices, recommendations, and earnings forecasts are informative and contain information about sixmonth post-event abnormal returns. Furthermore, Ivkovic and Jegadeesh (2004) provide evidence that the 
informativeness of analysts' recommendation revisions increase before the firm's earnings announcement date, indicating that the investment value of analysts' earnings forecasts and recommendations stems more from their independent collection of information than from the interpretation of public information, such as management earnings guidance. This result provides a strong motive for this study to use analyst recommendations as a proxy for private information. Mikhail et al. (2004) provide evidence of persistence in analyst stock picking ability and show that analysts who have issued more (or less) profitable recommendations in the past tend to issue more (or less) profitable recommendations in the future. Finally, Green (2006) shows that early access to stock recommendations provides investors with a significant investment value with $1.5 \%$ two day returns by shorting stocks with downgrade recommendation after controlling for transaction costs, and that short-term profit opportunities persist for only two hours following the premarket release of analyst recommendation changes.

\subsection{Informativeness of Short Selling}

Early empirical work in this area utilizes monthly short interest data and provides evidence that short sellers are sophisticated and well-informed investors. For example, Asquith and Meulbroek (1996) provide evidence that short sellers successfully identify securities that subsequently under-perform in the market. By examining private information about firms' earnings announcements, Senchack and Starks (1993) test the stock price reaction to earnings announcements and find that the greater the change in unexpected short interest, the more negative is the market reaction to short interest. In addition, Dechow et al. (2001) examined the informativeness of short selling by linking the short interest with stock's fundamental ratios, such as size and book to market ratio. They found that short sellers were able to identify over-valued stocks. Furthermore, Desai et al. (2002) examine the relationship between the level of short interest and stock returns on the NASDAQ from 1988 to 1994 and find that heavily shorted stocks experience significant negative abnormal annual return of up to $-13.56 \%$ after controlling for market return, firm size, book to market, and momentum factors.

Monthly short interest data only provides a static shot of the short selling activities during an entire month and is unable to capture the short-term pattern for short sellers' behavior. It is very likely that the speed of price adjustment may occur in an intra-day fashion. By using daily short sales data researchers are able to take a closer look at short sellers' behavior and conduct empirical tests that deliver more convincing evidence. For example, using intra-day short selling data from the Australia Stock Exchange, Aitken et al. (1998) find that short sales are negatively associated with stock returns, and provide evidence that short sales around information events are associated with a larger stock price reaction. In the U.S., Christophe et al. (2004) use a unique daily short selling dataset from NASDAQ's automated confirmation transaction service (ACT) to investigate the short selling before earnings announcements. They find that abnormal short selling is significantly related to post announcement stock returns, and that the level of pre-announcement short selling mostly appears to reflect firm specific information rather than the fundamental characteristics. In addition, Bohmer et al. (2006) use NYSE SuperDot system data associated with short selling from 2000 to 2004, and find that short sellers are extremely well informed. They document that stocks with heavy shorting under-perform by $1.16 \%$ in the following 20 days, and that institutional non-program short sales and large short selling orders are most informative.

More recently, when Regulation SHO data, an intra-day short selling dataset that covers all listed companies in a given Exchange became available, many researchers used this comprehensive and high frequency data to re-examine the short sellers' behavior during a short period, from 2005 to 2006 . For example, using NASDAQ SHO data for the first 6 months of 2005, Diether et al. (2009b) find that increasing short sales predicts future negative return, and that small trades have high predictive power.

\subsection{Short Sale Constraints and Stock Price Efficiency}

A large body of literature has revolved around the themes of information arrival and stock price efficiency in the context of short sale constraints. For example, Miller (1977) argues that short sale constraints prevent negative information from being registered into the stock price by restricting pessimistic investors from short selling while imposing no such restriction for optimistic investors, leading to an upwardly biased stock price, especially when investors' opinions diverge. Similarly, Diamond and Verrecchia (1987) develop a rational expectations model in which investors take short sale constraints into consideration in formulating their trading decisions. They argue that 
short sale constraints limit trades from both informed and uninformed short sellers and reduce stock price informational efficiency, especially on the private bad news side. Their model shows that the loss of informational efficiency from short sale constraints increases the risk as perceived by less informed investors, thus driving down the security price.

Empirically, Bris et al. (2007) examine the shorting-efficiency relation in 46 different countries by using delayed price response to market shocks as a proxy for price efficiency. They found that stock price in countries with constraints in place are less efficient than those where investors are allowed to short stocks. In addition, Saffi and Sigurdsson (2010) compared short selling in 26 markets around the world, and found that short sale constraints are associated with lower price efficiency measured by the correlation between contemporaneous stock returns and lagged market returns and the R square of a market model regression. More recently, Boehmer and Wu (2013) used the dispersion of the pricing error as the measure of informational efficiency of stock prices and found that increased daily short selling activities due to suspension of the uptick rule for pilot stocks directly drove the improvement in price efficiency. These studies, due to the data frequency limitation, focus on various types of price efficiency measures and daily evidence on the shorting-efficiency relation. In this study, high-frequency data allows us to use the speed of stock price response to analyst downgrades as an intra-day measure of price efficiency.

\section{DATA AND SAMPLES}

The short selling data is from the Regulation SHO dataset. The SEC chosen pilot stocks from the Russell 3000 membership list. All securities in the Russell 3000 Index were ranked by average daily dollar trading volume for the previous year. Then, every third stock was chosen as the pilot stock, and the remaining stocks are "control stocks". The Russell 3000 membership lists are obtained from the Russell Company. To eliminate the potential effect of index inclusion or index exclusion on stock returns, this study requires that sample stocks are members of the Russell 3000 index after the June 2004 reconstitution and remained in the Russell 3000 member list after the June 2005 reconstitution. Thus, stocks that were added to the index due to IPOs during the period June 2004 through 2005 are excluded, as well as stocks that were eliminated during the same period due to mergers, bankruptcies, and ticker changes. The control sample was obtained by excluding stocks on pilot stock list as of May 2, 2005, which is roughly twice as large as the pilot sample. As the results of these screens, our samples consist of 464 pilot stocks and 826 control stocks listed on the NYSE.

To examine the impact of the uptick rule on stock price efficiency, I compare stock price responses to analyst downgrades from May to December of 2005, a period featured by the different short sale constraints for pilot and control stocks. I define this period as the post-SHO period. If the suspension of the uptick rule contributes to the different price response patterns for the pilot and control sample, then similar intra-day price response patterns before the Pilot Program will be seen, when pilot stocks and control stocks have the identical treatment on the short selling price test restrictions. Therefore, I also examine stock price response to analyst downgrades for pilot and control stocks from January to April of 2005, a period featured by the same uptick rule treatment for the pilot and control stocks. This period is defined as the pre-SHO period. Tick-by-tick stock trade prices were obtained from the NYSE TAQ data set. Stock returns, trading volume, and other firm specific characteristic variables are extracted from the Center for Research in Securities Price (CRSP) and COMPUSTAT. Data for financial analysts' recommendations for stocks in our samples were obtained from Frist Call dataset. The recommendation value is defined as followings: one is "buy"; two is "overweight"; three is "neutral"; four is "underweight"; five is "sell"; and zero is the initiation of recommendation. To examine the stock price response to an information event, it is important to ensure that investors have access to these analyst recommendations. In this section, I focus on analyst downgrades that are released outside of regular trading hours, either before 9:30am or after 4:00pm, and examine the stock price response after the open at 9:30 am. Further, to ensure that the analyst recommendation represent significant information events that have material impact on stock value, this study focuses on stock recommendations issued by the 20 highest rated U.S. brokerage research departments, as designated by Institutional Investor. To measure the informational significance of downgrades, recommendation changes are defined here as the difference between the previous recommendation and the current recommendation for the same brokerage firm. For the initiation of recommendation, the recommendation change is specified as the deviation of the current recommendation from the neutral recommendation with the rating value of 3 . For example, if brokerage firm $X$ initiates a research on stock $Y$ with a rating of 1 or buy, then the recommendation change is $3-1=2$, representing an 
upgrade recommendation. On any given day, if there are multiple recommendation changes for one stock, a simple average of those changes is taken as the value of the recommendation change on that date for that stock. Finally, a recommendation change is classified as a downgrade if the value of a recommendation change is negative, as an upgrade if the value of the recommendation change is positive. Table 1 presents the number of upgrades and downgrades for samples. It shows that the mean and the distribution of downgrade magnitude for both pilot and control stocks. The differences between pilot- and control-stocks are not statistically distinguishable. Pre-SHO represents a period from January to April of 2005 and Post-SHO represents a period from May to December of 2005.

Table 1. Descriptive Statistics for Analyst Downgrades

\begin{tabular}{lcc|cc}
\hline & \multicolumn{2}{c|}{ Pre-SHO } & \multicolumn{2}{c}{ Post-SHO } \\
\hline & Pilot & Control & Pilot & Control \\
\hline \# of downgrades & 143 & 373 & 277 & 605 \\
Mean value of downgrades & -1.97 & -2.02 & -1.45 & -1.46 \\
Stderr of mean values & 0.021 & 0.015 & 0.015 & 0.011 \\
\hline Distribution of downgrades & & & & $0.71 \%$ \\
\hline$\%$ of -4 downgrades & $5.05 \%$ & $5.02 \%$ & $4.26 \%$ & $4.24 \%$ \\
$\%$ of -3 downgrades & $23.91 \%$ & $26.10 \%$ & $35.57 \%$ & $35.11 \%$ \\
$\%$ of -2 downgrades & $33.96 \%$ & $34.31 \%$ & $59.53 \%$ & $59.94 \%$ \\
$\%$ of -1 downgrades & $37.08 \%$ & $34.57 \%$ & & \\
\hline
\end{tabular}

\section{EMPIRICAL TESTING}

\section{1 Stock Price Response to After-Hour Analyst Downgrades for Pilot and Control Stocks}

This study hypothesizes that short sale constraints hamper stock price efficiency upon the arrival of analyst downgrade information. The uptick rule is adopted as the proxy of the short sale constraint in this paper. To directly examine whether short sale constraints hamper stock price efficiency I examine the speed of the stock price response on the day that analyst downgrades become publicly available for both pilot and control stocks. This method has several advantages. First, it is a simple, direct, and straightforward way to measure the stock price efficiency. Second, it examines the informational efficiency of stock prices in the context of true information setting, namely, analyst recommendations. Third, it uses the uptick rule as the proxy for short sale constraint, which is least likely to be subject to endogeneity concerns. Finally, it provides closer and more magnified evidence on how price response actually occur for short sale constrained stocks (control stocks) and less short sale constrained stocks (pilot stocks).

The Kim et al. (1997)'s mean-adjusted method is used to compute abnormal returns. Mean returns are calculated for each stock at the estimation period, day-50 to -3 . To examine the timing of those price responses, stock abnormal returns are calculated for each time intervals on the event day, including the opening returns, for each analyst downgrade during both the pre- and post-SHO periods. Then I compare over time the sizes of the average abnormal price response for pilot- and control-stocks.

During the pre-SHO period, the uptick rule is imposed for both pilot and control stocks, I would expect the similar price response pattern for these stocks. During the post-SHO period, the uptick rule is suspended for pilot stocks. The relaxation of the short sale constraints should improve the price efficiency in pilot stocks. I expect that it takes much less time for the market to respond to the analyst downgrades in pilot stocks than in control stocks.

Table 2 reports average abnormal returns during the market opening (4:00pm-9:30am), five-minute intervals between 9:30am and 10:30am, and time intervals 10:30am-12:00am, 12:00-3:00pm, and 3:00-4:00pm for pilot- and control-stocks during both pre- and post-SHO periods. These returns are graphed in Figure 1 (pre-SHO period) and Figure 2 (post-SHO period). The average abnormal returns in a given intervals is obtained by average across the sample stocks. I use t-tests with the standard error computed across sample stocks to evaluate the significance of the average abnormal returns in a given interval. 
Table 2. Stock Price Responses to Analyst Downgrades on NYSE

\begin{tabular}{|c|c|c|c|c|c|c|c|c|}
\hline \multirow[b]{2}{*}{$\begin{array}{c}\text { Time- } \\
\text { interval }\end{array}$} & \multicolumn{4}{|c|}{ Pre SHO } & \multicolumn{4}{|c|}{ Post SHO } \\
\hline & Pilot & Control & Diff & t-stat & Pilot & Control & Diff & t-stat \\
\hline & (1) & (2) & $\begin{array}{c}(3)= \\
(1)-(2)\end{array}$ & & (4) & (5) & $\begin{array}{c}(6)= \\
(4)-(5)\end{array}$ & \\
\hline 16:00-9:30am & $\begin{array}{c}-2.44 \% * * * \\
(0.0033)\end{array}$ & $\begin{array}{c}-2.22 \% * * * \\
(0.0028)\end{array}$ & $-0.22 \%$ & -0.51 & $\begin{array}{c}-2.96 \% * * * \\
(0.0032)\end{array}$ & $\begin{array}{c}-2.10 \% * * * \\
(0.0029)\end{array}$ & $-0.86 \% * *$ & -1.99 \\
\hline $9: 30-9: 35 \mathrm{am}$ & $\begin{array}{c}-0.58 \% * * \\
(0.0028)\end{array}$ & $\begin{array}{c}-0.62 \% * * * \\
(0.002)\end{array}$ & $0.04 \%$ & 0.12 & $\begin{array}{l}-0.23 \% \\
(0.0021)\end{array}$ & $\begin{array}{c}-0.73 \% * * * \\
(0.0014)\end{array}$ & $0.50 \% * *$ & 1.98 \\
\hline 9:35-9:40am & $\begin{array}{c}-0.18 \% \\
(0.0029)\end{array}$ & $\begin{array}{l}-0.16 \% \\
(0.002)\end{array}$ & $-0.02 \%$ & -0.06 & $\begin{array}{l}-0.08 \% \\
(0.0021)\end{array}$ & $\begin{array}{l}-0.15 \% \\
(0.0015)\end{array}$ & $0.07 \%$ & 0.27 \\
\hline $9: 40-9: 45 \mathrm{am}$ & $\begin{array}{l}-0.07 \% \\
(0.003) \\
\end{array}$ & $\begin{array}{c}-0.15 \% \\
(0.0021) \\
\end{array}$ & $0.08 \%$ & 0.22 & $\begin{array}{l}-0.01 \% \\
(0.0021) \\
\end{array}$ & $\begin{array}{c}-0.07 \% \\
(0.0015) \\
\end{array}$ & $0.06 \%$ & 0.23 \\
\hline $9: 45-9: 50 \mathrm{am}$ & $\begin{array}{l}-0.06 \% \\
(0.003) \\
\end{array}$ & $\begin{array}{c}-0.02 \% \\
(0.0021) \\
\end{array}$ & $-0.04 \%$ & -0.11 & $\begin{array}{c}-0.05 \% \\
(0.0022) \\
\end{array}$ & $\begin{array}{c}-0.10 \% \\
(0.0015)\end{array}$ & $0.05 \%$ & 0.19 \\
\hline $9: 50-9: 55 \mathrm{am}$ & $\begin{array}{l}-0.03 \% \\
(0.003) \\
\end{array}$ & $\begin{array}{c}-0.01 \% \\
(0.0022) \\
\end{array}$ & $-0.02 \%$ & -0.05 & $\begin{array}{c}0.02 \% \\
(0.0022) \\
\end{array}$ & $\begin{array}{c}0.08 \% \\
(0.0015) \\
\end{array}$ & $-0.06 \%$ & -0.23 \\
\hline 9:55-10:00am & $\begin{array}{l}-0.03 \% \\
(0.003)\end{array}$ & $\begin{array}{c}0.00 \% \\
(0.0022)\end{array}$ & $-0.03 \%$ & -0.08 & $\begin{array}{c}0.02 \% \\
(0.0021)\end{array}$ & $\begin{array}{l}-0.12 \% \\
(0.0015)\end{array}$ & $0.14 \%$ & 0.54 \\
\hline $\begin{array}{l}\text { 10:00- } \\
\text { 10:05am }\end{array}$ & $\begin{array}{l}-0.03 \% \\
(0.0031)\end{array}$ & $\begin{array}{l}-0.05 \% \\
(0.0022)\end{array}$ & $0.02 \%$ & 0.05 & $\begin{array}{c}0.02 \% \\
(0.0022)\end{array}$ & $\begin{array}{c}0.00 \% \\
(0.0015)\end{array}$ & $0.02 \%$ & 0.08 \\
\hline $\begin{array}{l}10: 05- \\
10: 10 \mathrm{am}\end{array}$ & $\begin{array}{l}0.00 \% \\
(0.003)\end{array}$ & $\begin{array}{l}-0.01 \% \\
(0.0023)\end{array}$ & $0.01 \%$ & 0.03 & $\begin{array}{c}0.00 \% \\
(0.0022)\end{array}$ & $\begin{array}{l}-0.02 \% \\
(0.0015)\end{array}$ & $0.02 \%$ & 0.08 \\
\hline $\begin{array}{l}10: 10- \\
10: 15 \mathrm{am}\end{array}$ & $\begin{array}{l}-0.01 \% \\
(0.0031)\end{array}$ & $\begin{array}{c}0.00 \% \\
(0.0023)\end{array}$ & $-0.01 \%$ & -0.03 & $\begin{array}{c}0.01 \% \\
(0.0022)\end{array}$ & $\begin{array}{l}-0.02 \% \\
(0.0015)\end{array}$ & $0.03 \%$ & 0.11 \\
\hline $\begin{array}{l}10: 15- \\
10: 20 \mathrm{am}\end{array}$ & $\begin{array}{c}0.04 \% \\
(0.0031)\end{array}$ & $\begin{array}{l}-0.01 \% \\
(0.0023)\end{array}$ & $0.05 \%$ & 0.13 & $\begin{array}{c}0.00 \% \\
(0.0022)\end{array}$ & $\begin{array}{l}-0.03 \% \\
(0.0015)\end{array}$ & $0.03 \%$ & 0.11 \\
\hline $\begin{array}{l}10: 20- \\
10: 25 \mathrm{am}\end{array}$ & $\begin{array}{l}-0.04 \% \\
(0.0032)\end{array}$ & $\begin{array}{l}-0.02 \% \\
(0.0023)\end{array}$ & $-0.02 \%$ & -0.05 & $\begin{array}{c}0.02 \% \\
(0.0022) \\
\end{array}$ & $\begin{array}{c}0.00 \% \\
(0.0015) \\
\end{array}$ & $0.02 \%$ & 0.08 \\
\hline $\begin{array}{l}10: 25- \\
10: 30 \mathrm{am}\end{array}$ & $\begin{array}{l}-0.03 \% \\
(0.0032)\end{array}$ & $\begin{array}{c}0.00 \% \\
(0.0023)\end{array}$ & $-0.03 \%$ & -0.08 & $\begin{array}{c}0.01 \% \\
(0.0022)\end{array}$ & $\begin{array}{c}0.00 \% \\
(0.0015)\end{array}$ & $0.01 \%$ & 0.04 \\
\hline $\begin{array}{l}10: 30- \\
12: 00 \mathrm{pm}\end{array}$ & $\begin{array}{l}-0.04 \% \\
(0.0032)\end{array}$ & $\begin{array}{l}-0.07 \% \\
(0.0024)\end{array}$ & $0.03 \%$ & 0.07 & $\begin{array}{l}-0.14 \% \\
(0.0023)\end{array}$ & $\begin{array}{l}-0.12 \% \\
(0.0015)\end{array}$ & $-0.02 \%$ & -0.07 \\
\hline $12: 00-3: 00 \mathrm{pm}$ & $\begin{array}{l}-0.10 \% \\
(0.0034)\end{array}$ & $\begin{array}{c}0.06 \% \\
(0.0023)\end{array}$ & $-0.16 \%$ & -0.39 & $\begin{array}{l}-0.03 \% \\
(0.0024)\end{array}$ & $\begin{array}{l}-0.04 \% \\
(0.0015)\end{array}$ & $0.01 \%$ & 0.04 \\
\hline $3: 00-4: 00 \mathrm{pm}$ & $\begin{array}{c}-0.09 \% \\
(0.0036)\end{array}$ & $\begin{array}{c}-0.10 \% \\
(0.0024)\end{array}$ & $0.01 \%$ & 0.02 & $\begin{array}{c}0.13 \% \\
(0.0024)\end{array}$ & $\begin{array}{c}0.04 \% \\
(0.0016)\end{array}$ & $0.09 \%$ & 0.31 \\
\hline
\end{tabular}

The standard errors are presented in parentheses below the means. Diff is the difference of abnormal stock returns for each time interval between pilot and control samples. $*, * *, * *$ are significant at $10 \%, 5 \%$, and $1 \%$ level, respectively.

During the pre-SHO period, for both pilot and control stocks, the average abnormal returns during the market opening is $-2.44 \%$ and $-2.22 \%$, respectively. Both are statistically significant at $1 \%$ level. The average abnormal returns during the first five-minute interval after the opening are $-0.58 \%$ and $-0.62 \%$ for pilot and control stocks. Both are statistically significant. The average abnormal returns in the subsequent intervals are small and not significant for both pilot and control stocks. Results here indicate that most of the information contained in analyst downgrades is reflected stock prices at the opening trade and trades that occur with the succeeding five minutes. Comparing abnormal returns for pilot and control stocks, there are no statistically significant differences for all time intervals. It indicates that during the pre-SHO period when the uptick rule is equally binding for all stocks, stock price responses following the release of analyst downgrades are similar for pilot and control stocks. 
Figure 1. Stock Price Response to After-hour Downgrades during the pre-SHO Period

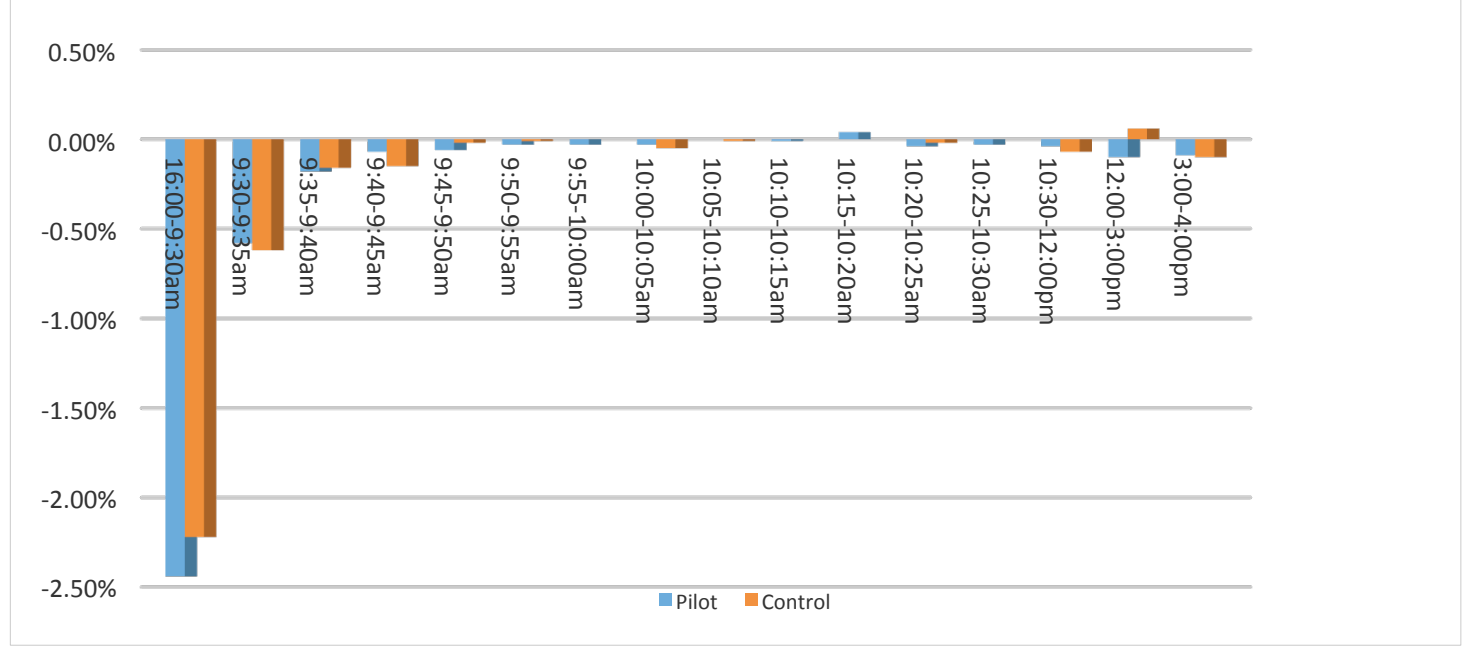

During the post-SHO period, however, the average abnormal returns during the market opening are $-2.96 \%$ and $-2.10 \%$ for pilot and control stocks, with the difference statistically different at $5 \%$ level. The average abnormal return during the first five-minute interval for pilot stocks is not significantly different from zero, while the average abnormal return during the same interval for control stocks is $-0.73 \%$, statistically significant at $1 \%$ level. The difference between pilot and control stocks is statistically significant at 5\% level. Results here indicate that when the uptick rule is suspended for pilot stocks, virtually all information contained in the analyst downgrades has been incorporated into stock prices during the market opening, and it takes an extra five minutes for control stocks to impound all negative information into stock prices. Overall, results in Table 2 suggests that the suspension of the uptick rule during the post-SHO period speed up the stock price responses to after-hour analyst downgrades by up to five minutes. The opening prices for pilot stocks better reflect the downgrade information than those of control stocks. In other words, informational price efficiency measured by the speed of price response to downgrades has been improved when short sale constrains are removed.

Figure 2. Stock Price Response to After-hour Downgrades during the Post-SHO Period

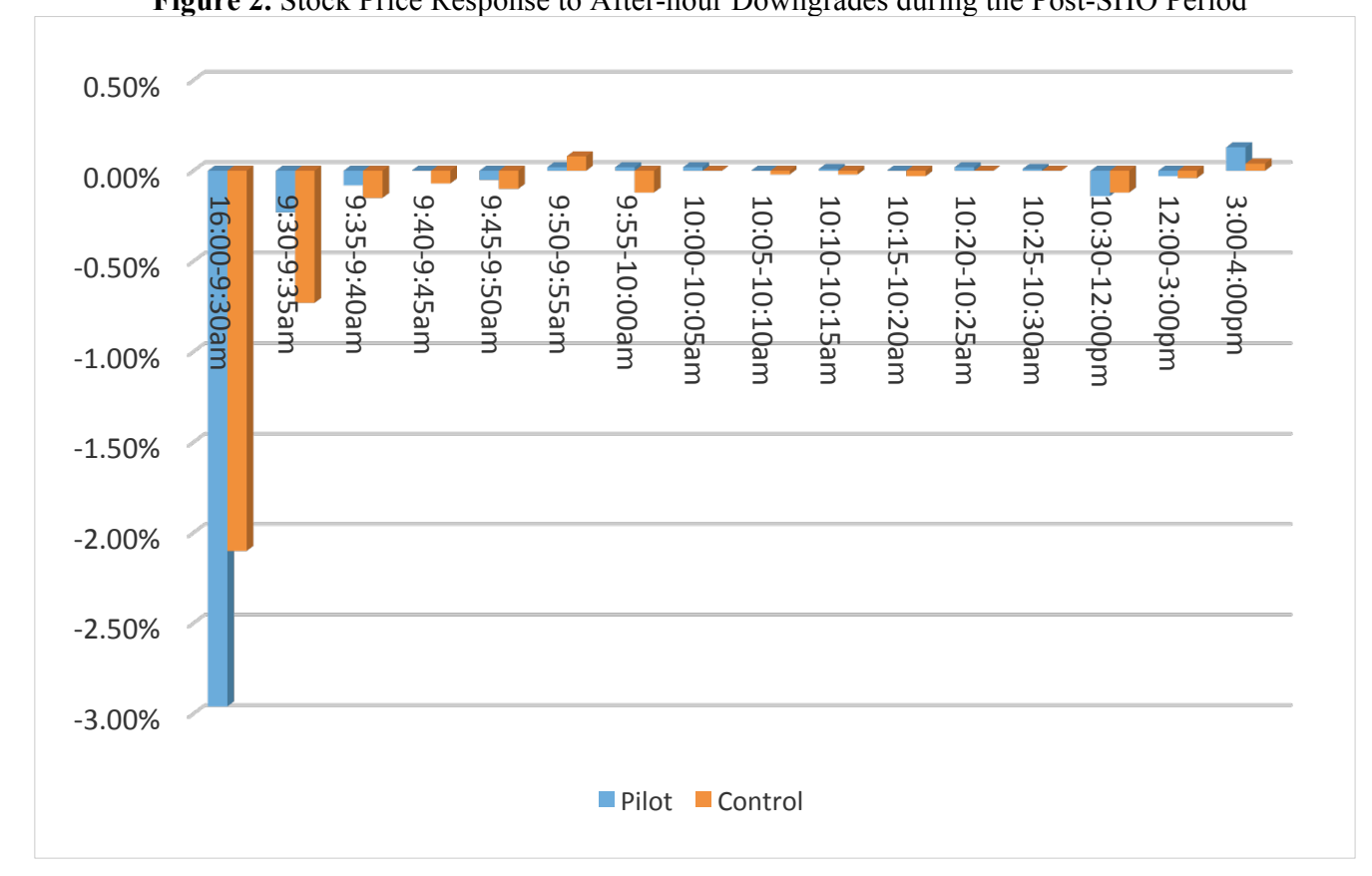


There are several possible reasons other than uptick rule restrictions why pilot stock prices would respond more rapidly to downgrades than control stocks. First, the samples may not perfectly matched. The number of observations in the control sample is about twice as many as in the pilot sample. Also, these two samples are not matched on firm size and book-to-market ratio. These variables are important in numerous studies and may be important here. Second, all downgrades are treated equally without considering whether it is a downgrade from a relatively good recommendation to a neutral recommendation, or a downgrade from a bad one to a worse one. If the market responds differently to different types of downgrades, then differences in the samples of pilot and control downgrades will result in different price responses for pilot and control stocks.

To address these robustness issues, first, pilot and control samples are matched on firm size and book-tomarket ratio. Second, a distinction is made between "not so good" downgrades and "really bad" downgrades, and the tests run for these two sub-samples. "Not so good" downgrades are defined as the recommendation changes from "buy" to "overweight" or from "overweight" to "neutral". The "really bad" downgrades are recommendation changes from "neutral" to "underweight" or from "underweight" to "sell".

Robustness test results consistently show the improved stock price efficiency for the pilot stocks during the post-SHO periods. To save the space, robustness test results are not presented but available upon requests.

\subsection{Stock Price Response to Analyst Downgrades During Normal Trading Hours}

Boehmer and $\mathrm{Wu}$ (2013) show that increased short selling activity associated with the suspension of uptick rules for pilot stocks directly improves stock price efficiency. But when this study examined the stock price efficiency in a direct intra-day fashion, the results show that short selling activities on the downgrade recommendation day do not directly contribute to the quicker stock price response to bad news because virtually all downgrade information has been incorporated into stock price before the market opens. To determine whether short selling is responsible for this price improvement it is necessary to examine shorting immediately before the downgrade event. In this section I investigate the intra-day price response and short selling around downgrade recommendations that occur during normal trading hours.

From the full sample of downgrade recommendations, I select those published during the normal trading hours from 11:30am to 2:00 pm. To ensure that these recommendations constitute substantial negative surprises, I require that these downgrades follow a prior upgrade. The final sample includes 133 control stock downgrades and 78 pilot stock downgrades. Then I calculate the five-minute cumulative returns for a four-hour period beginning two hours before the release time of the recommendation and ending two hours after the release time. The returns between market opening and two hours before the recommendations are also calculated for both samples to account for possible information leakage before the recommendation downgrades. 
Figure 3. Stock Price Response to Downgrades during Normal Trading Hours during the Post-SHO Period

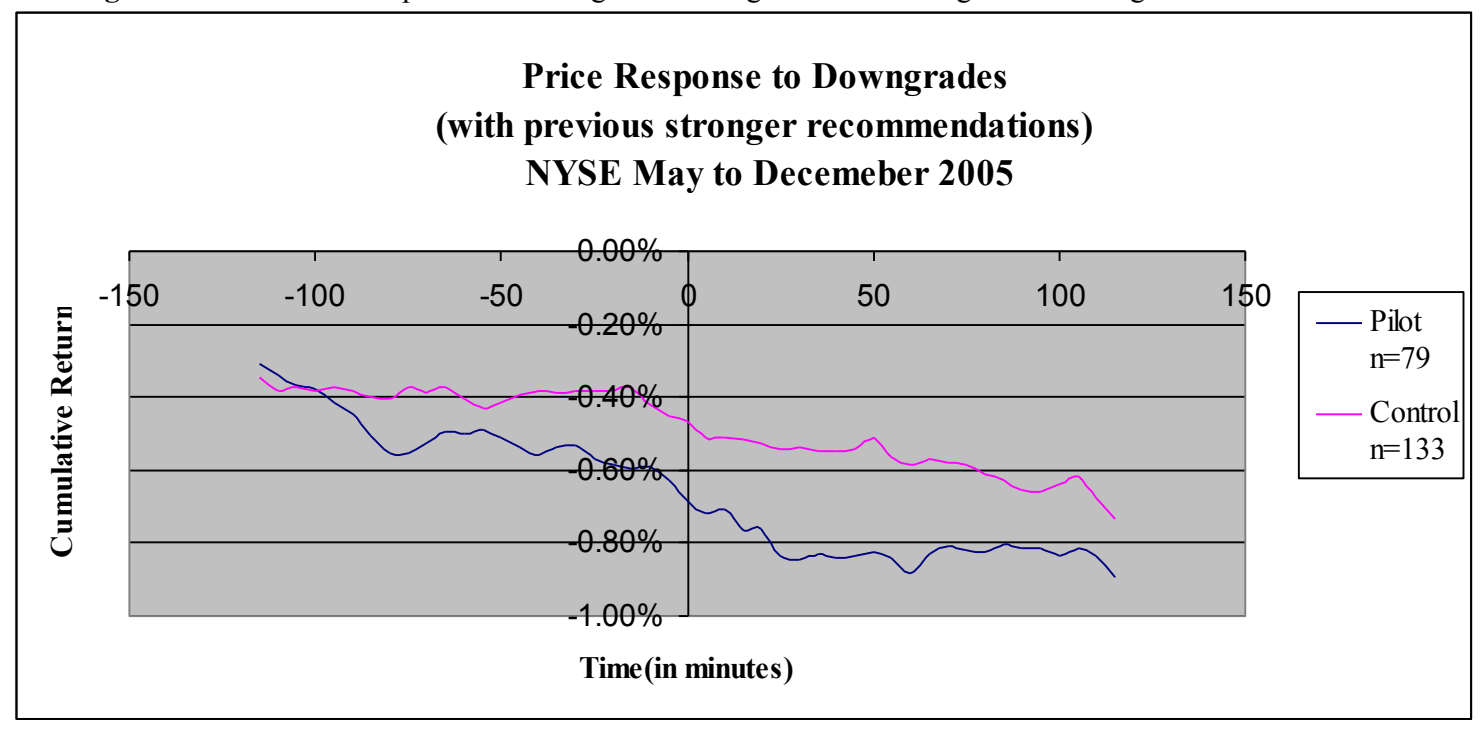

Figure 3 graphs the intra-day return paths around the normal trading-hour downgrades for both pilot and control samples. It shows a more complete intra-day picture, which reveals that the pre-recommendation short selling may contribute to the enhanced price efficiency for pilot stocks. When the downgrade recommendation is released to the market at time 0 , pilot stocks respond to bad news quicker and with greater magnitude. Pilot stocks begin to respond to the downgrade announcement approximately 85 minutes before the announcement, while there is no significant price response before the announcement for control stocks. This suggests that the suspension of the uptick rule on pre-recommendation short selling appears to contribute to the enhanced price efficiency for pilot stocks. This is a reasonable outcome, because, while informed short sellers are prevented from submitting shorting orders due to the uptick rule restrictions in control stocks when the stock price is declining. Now they can do so in pilot stocks by freely submitting down-tick shorting orders to take advantage of their private information, pushing stock prices down before the recommendation announcement.

\subsection{Shorting Activity and Stock Price Efficiency}

So far, it has been established that pilot stocks with no uptick rule restrictions respond to negative news contained in analyst downgrades more quickly than control stocks. But it has not been established that any shorting activity actually accompanies this price response. To test if there is a direct link between the pre-recommendation pilot stock price decline and short selling, I further examine the short selling activities around normal trading hour recommendations.

The short ratio is calculated in every five minute interval as the ratio of the short volume during that interval to the average daily trading volume. This short ratio is then cumulated, starting two hours before the announcement and ending two hours after the announcement. Surprisingly, there is no significant difference in short selling between the pilot and the control sample. Pilot and control stocks are shorted about the same amount around a downgrade. However, Figure 3 suggests that pilot shorting activity is more effective at driving down the price. It is possible that there is a difference in market maker activity between the pilot and control stocks that may account for the differential price response. The SHO dataset lists the short classification entered for each transaction. A short trade is classified as either "short," indicating that it would ordinarily be subject to a tick test rule, or "exempt," indicating that it is exempt from a tick test rule, typically because the trade is made on behalf of a market-maker or dealer. During the SHO test period all trades on pilot stocks are technically "exempt" but dealers for the most part continued to mark them "short" and "exempt" and relied on the processing center to exempt pilot stocks from the tick test rule. This leaves us with a record of dealer (exempt) versus non-dealer (non-exempt) shorting activity for both pilot and control stocks. 
Next, I proceed to separate short sale exempt orders submitted by market dealers who rely on the uptick rule exemption provisions in Rule 10a-1 from non-exempt orders. Results show that non-exempt short selling activities measured as a percentage of the average daily trading volume are smaller for pilot stocks than control stocks during the entire trading day, and that exempt short selling is greater for pilot stocks than for control stocks. This suggests that short selling around downgrades shifted from informed traders to market dealers.

The analysis in this section reveals two possible activities that help to explain the relation between short selling and improved price efficiency. The first is that informed short sellers are less likely to short pilot stocks before downgrades, possibly because of concerns that short selling on pilot stocks will be more highly scrutinized than on control stocks. However, the remaining downtick shorting orders are still quite effective in pushing the price down. The second is that, as market makers and dealers observe reduced shorting in pilot stocks, they fill the liquidity gap to facilitate trading. These shorting orders may actually push the stock price down and help to improve price efficiency.

It could be that short seller intentionally reduce their informed shorting during a two hour period prior to the recommendation due to the regulatory scrutiny during the Pilot Program. However, this conclusion is not strong due to the small sample size with only 89 observations for pilot stocks and 133 observations for control stocks. Also, identifying shorts marked as "non-exempt" as normal short sellers' shorts might be problematic. About $0.5 \%$ of shorting orders are exempt from uptick rule tests during the pre-SHO period, while this percentage increased dramatically during the post-SHO period with $2.5 \%$ for control stocks and about $18 \%$ for pilot stocks. According to Regulation SHO, all shorting orders in pilot stocks should be marked as "exempt" during the post-SHO period. But shorting orders from market dealers submitted directly through the clearing house may be automatically marked as "non-exempt" orders. Considering this possibility, shorts marked as "exempt" may include shorts from both market dealers and normal short sellers.

\subsection{Discussion of the Market Opening Mechanism}

Thus far, neither normal-hour shorting on the recommendation day nor pre-recommendation shorting flows could explain the improved pilot stock price efficiency. It appears that short selling that occurs before day 0 may contribute to the improved price efficiency when the uptick rule restrictions are suspended for pilot stocks.

Before Regulation SHO, short selling is allowed at the opening auction as long as it follows the 10a-1 rule which only allows uptick short selling orders. In the NYSE, short selling with minus tick at the opening is only allowed for certain types of foreign securities. After regulation SHO, however, downtick or zero-tick short selling at the open became available for non-exempt traders of pilot stocks. These added short sales may contribute to the enhanced stock price efficiency. When the NYSE specialists build open book, they observe many downtick short selling orders from aggressive short sellers. The batch auction mechanism at the NYSE opening may induce more short selling orders from aggressive short sellers, because it provides an opportunity for price improvement at the opening price. Also, specialists in the NYSE have a legal responsibility to share the open book information with other brokers and dealers, who may further share such information with institutional investors. Consequently, aggressive short sellers who held the most pessimistic opinions will be encouraged to submit more short selling orders with the lowest price. Ultimately, the competition amongst the aggressive short sellers at the opening auction greatly facilitates the process of impounding negative information into stock price before the market open bell. Note, however, that the opening return also includes any price change due to after-hour trading before the open. Therefore, it could be that both after-hour shorting and the market opening shorting orders contribute to the enhanced stock price efficiency when the uptick rule restrictions are removed. One of the limitations of this paper is that the lack of data on after-hours shorting and short selling orders at the market opening limits the ability of this study to further test this promising conjecture.

\section{CONCLUSIONS}

This study hypothesizes that short sale constraints hamper stock price efficiency upon arrival of analyst downgrades. By examining the speed of which stock price response to analyst downgrades for pilot (short sale nonconstrained) stocks and control (short sale constrained) stocks, I find evidence supporting this hypothesis. For after- 
hours downgrades, pilot stocks respond quickly, with virtually all of the price response incorporated by the following open, while control stocks take an extra five minutes after opening to fully reflect the new information. Results are robust after accommodating size and book-to-market ratio matched sample and distinguishing "not so good" downgrades from "really bad" downgrades. To further investigate the role of short selling activity, I examine stock price response to analyst downgrades that occur during normal trading hours. It shows that downgrade information is partially incorporated into pilot stock prices up to two hours before the recommendation is released, while control stocks take up to an hour and a half after the release to impound the information into stock price, confirming that short sale constraints lower stock price efficiency. In addition, the pre-recommendation price decline in pilot stocks is associated with lower levels of non-exempt shorting and higher levels of exempt shorting. Given lower levels of informed shorting, observed rapid price response occurs. This is consistent with the hypothesis that short sale constraints reduce the efficiency in which new information are impounded into stock prices.

The main findings of this paper lends credit to future research that utilizes data of after-hour shorting and shorting orders at the market opening auction to examine the importance of both after-hour trading and market opening in improving stock price efficiency when short sale constraints are relaxed.

\section{AUTHOR INFORMATION}

Kevin Zhao earned a Ph.D. in Finance from the University Tennessee, an M.B.A. from the University of South Carolina, and a B.A. from Peking University. He joined MTSU in 2008. Dr. Zhao's research lie in Investments, Corporate Governance, and International Economics and Finance. He has published peer-reviewed research in journals such as Journal of Applied Business Research, Journal of Economics and Finance, Applied Financial Economics, and so on. His research has been presented at national and international conferences. At MTSU, Dr. Zhao teaches Investments, Portfolio Theory and Management, Business, Finance, and TVA Investment Challenge. E-mail: kevin.zhao@mtsu.edu

\section{REFERENCE}

Alexander, G. J. and Peterson, M. A. (2008). The effect of price tests on trader behavior and market quality: an analysis of Reg SHO, Journal of Financial Markets, 11, 84-111.

Aitken, M., Frino, A., McCorry, M.S., and Swan, P.L. (1998), Short Sales are Almost Instantaneously Bad News: Evidence from the Australian Stock Exchange, Journal of Finance, 53, 2205-2223

Asquith, P., Pathak, P. A. and Ritter, J. R. (2005). Short interest, institutional ownership, and stock returns, Journal of Financial Economics, 78, 243-276.

Barber, B., Lehavy,R., McNichols, R.M. and Trueman, T (2001), Can Investors Profit from the Prophets? Security Analyst Recommendations and Stock Returns, Journal of Finance, 56 (2), 531-563.

Boehmer, R. D., Danielsen, B. R. and Sorescu, S. M.(2006). Short sale constraints and overvaluation, Journal of Financial and Quantitative Analysis, 41, 455-488.

Boehmer, E. and Wu, J. (2013), Short Selling and the Price Discovery Process, Review of Financial Studies, 26(2), 287-322.

Brav, A. and Lehavy, R. (2003), An Empirical Analysis of Analysts' Target Prices: Short-Term Informativeness and Long-Term Dynamics, Journal of Finance, 58 (5), 1933-1968.

Bris, A., Goetzmann,W.N., and Zhu, N. (2007), Efficiency and the Bear: Short Sales and Markets around the World, Journal of Finance, 63(3), 1029-1079.

Christophe, S., Ferri, M.G., and Angel, J. (2004), Short-Selling Prior to Earnings Announcements, Journal of Finance, 59: 1845-1876.

Dechow, R. M., Hutton, A. P., Meulbroek, L and Sloan, R. G. (2001). Short-sellers, fundamental analysis and stock returns, Journal of Financial Economics, 61, 77-106.

Desai, H., Ramesh, K., Thiagarajan, S. R. and Balachandran, B. V. (2002). An investigation of the informational role of short interest in the Nasdaq market, Journal of Finance, 57, 2263-2287.

Diamond, D. W. and Verrecchia, R. E. (1987). Constraints on short-selling and asset price adjustment to private information, Journal of Financial Economics, 18, 277-311.

Diether, K. B., Lee, K. H. and Werner, I. M. (2009a). It's SHO time: short-sale price tests and market quality, The 
Journal of Finance, 64, 37-73.

Diether, K.B., Lee, K.H., Werner, I.M. (2009b), Short Sale Strategies and Return Predictability, Review of Financial Studies, 22, 575-607.

Green, T.C. (2006), The Value of Client Access to Analyst Recommendations, Journal of Financial and Quantitative Analysis, 41(1), 1-24.

Ivkovic, Z. and Jegadeesh, N. (2004), The Timing and Value of Forecast and Recommendation Revisions, Journal of Financial Economics, 73, 433-463.

Kim, S.T., Lin, J.C., Slovin, M.B. (1997), Market Structure, Informed Trading, and Analyst Recommendations, Journal of Financial and Quantitative Analysis, 32 (4), 507-524.

Mikhail, M. B., Walther, B.R., and Willis, R.H. (2004), Do Security Analysts Exhibit Persistence Difference in Stock Picking Ability? Journal of Financial Economics, 74, 67-91.

Miller, E. (1977). Risk, uncertainty, and divergence of opinion, Journal of Finance, 32, 1151-1168.

Saffi, P. and Sigurdsson, K (2010), Price Efficiency and Short Selling, Review of Financial Studies, 24(3), 821-852.

Senchack, A.J., Jr. and Starks, L. (1993), Short-Sale Restrictions and Market Reaction to Short Interest Announcements, Journal of Financial and Quantitative Analysis, 28, 177-194.

Womack, K. (1996), Do Brokerage Analysts’ Recommendation Have Investment Value? Journal of Finance, 51 , 137-167. 